\title{
Aspectos biológicos no processo de reparo mediante tratamento expectante
}

\author{
Marcelo Filadelfo Silva ${ }^{1}$ \\ Livia Reis Carvalho ${ }^{2}$ \\ Fernando Mandarino ${ }^{3}$ \\ André Luiz Barrachini Centola ${ }^{3}$
}

\begin{abstract}
Resumo
A busca pela preservação da vitalidade pulpar, através da realização de procedimentos mais conservadores, representa um importante campo de estudo na odontologia. $\mathrm{O}$ tratamento expectante representa um procedimento restaurador, baseado em conhecimentos biológicos sobre o processo de progressão da lesão de cárie, através do estudo da natureza e características das respostas dos tecidos dentários a esse processo destrutivo. Trata-se de uma forma de terapia que é prática e segura e que pode ser indicada na odontologia restauradora moderna. A proposta deste estudo é realizar uma sucinta revisão de literatura sobre aspectos biológicos do complexo dentina-polpa, envolvidos no processo de reparo do dente submetido ao tratamento expectante.
\end{abstract}

Palavras-chave: dentina - polpa - tratamento expectante; dentina - polpa - microrganismos

\section{INTRODUÇÃO}

Polpa e dentina são tecidos integralmente conectados, no sentido de que reaçōes fisiológica e patológica de um tecido poderão afetar o outro (MJÖR; HEYIRAAS, 2001). Dos componentes estruturais que compõem o complexo dentina-polpa, atenção especial deve ser dada aos odontoblastos, células que estão localizadas na periferia da polpa, conectando-a à prédentina. Cada célula tem uma extensão dentro do túbulo dentinário, o chamado processo odontoblástico. Essas células são responsáveis tanto pela formação de dentina primária e de dentina fisiológica ou secundária (que é continuamente produzida durante toda a vida) quanto pelo mecanismo biológico que busca o bloqueio da evolução da cárie (HEYIRAAS; MJÖR, 2001).

Sempre que a polpa dental sofre algum tipo de injuria, direta ou indiretamente, o sistema imune desencadeia uma resposta inflamatória para limitar os danos causados, através da eliminação dos organismos invasores. (HEYIRAAS; MJÖR, 2001)

\footnotetext{
${ }^{1}$ Professor de Dentistica. Departamento de Saúde. UEFS. Feira de Santana - BA

${ }^{2}$ Cirurgião-dentista. Especialista em Periodontia. Prefeitura Municipal de Salvador. Salvador - BA

${ }^{3}$ Professor Titular. Departamento de Odontologia Restauradora. Faculdade de Odontologia de Ribeirão Preto - USP. Ribeirão Preto - SP

Correspondência para / Correspondence to:

Marcelo Filadelfo Silva

Av. Dom Eugênio Sales, Parque Solarium Pituaçu, Bloco 5, apt. 203 - Boca do Rio.

41.303-400 Salvador - Bahia - Brasil.

Tel: (71) 8826-6005; (71)461-6020.

E-mail-mfiladelfosilva@yahoo.com.br
} 
As mudanças teciduais associadas com a progressão rápida da cárie são representadas principalmente pela ausência de hipermineralização da dentina afetada, reação dos odontoblastos na região da pré-dentina e reação inflamatória na polpa em áreas localizadas adjacentes aos túbulos afetados (MJÖR; FERRARI, 2001).

Quando os odontoblastos são destruídos, em decorrência da rápida progressão da cárie, novas células da polpa se diferenciam em odontoblastos (MJÖR; FERRARI, 2001).

O dente possui uma capacidade de reação de defesa natural contra o ataque da cárie, que é caracterizada pela formação de dentina reparadora na polpa e pela esclerose dos túbulos afetados. Essa reação de defesa é concomitante com a paralisação da progressão da lesão, o que causa diminuição da permeabilidade dentinária. Em um ataque rápido, a dentina e a polpa não têm tempo para completar a reação de defesa. A lesão de cárie ativa resulta em um aumento da permeabilidade, o que pode causar dor e a exposição da polpa. O objetivo do tratamento clínico deverá ser paralisar todas as lesões ativas antes da colocação de materiais restauradores definitivos (BARBER; MASSLER, 1964).

Condições patológicas agressivas, como as cáries ativas de progressão rápida, causam a desintegração dos odontoblastos. Entretanto, o tecido pulpar possui células ectomesenquimais indiferenciadas, capazes de se diferenciarem em células como os odontoblastos, possibilitando, assim, a contínua formação de dentina reparadora (TZIAFAS; SMITH; LESOT, 2000).

O tecido pulpar e os odontoblastos possuem um enorme poder de recuperação.Trabalho realizado com germes de dentes auto-transplantados dentro do tecido subcutâneo de ratos, com o objetivo de avaliar a capacidade de recuperação da polpa, constatou que a mesma pode reverter quadros de injúria severa e prolongada e se recuperar depois de estados degenerativos que seriam considerados irreversíveis por imagens microscópicas (WEINREB; SHARAV; ICKOWICZ, 1967).

O mecanismo de formação da dentina esclerosada baseia-se num mecanismo ativo, representado pela deposição acelerada e contínua de matriz dentinária, indistinguível da dentina peritubular e sua posterior mineralização (BRADFORD, 1960).

As reaçôes da dentina e da polpa a cáries incipientes e avançadas variam, desde uma ligeira desordem da camada dentinária na cárie superficial, até uma zona de dentina reparadora, com e sem reação inflamatória pulpar. $\mathrm{O}$ complexo dentino-pulpar de um dente recém erupcionado, com esmalte e dentina imaturos, mostra mais reaçôes que tecidos mais velhos e menos permeáveis. Em todos os casos, exceto quando a polpa tenha sido agredida diretamente por algum instrumento ou invadida por microorganismos, a resposta é produtiva e não degenerativa. A esclerose da dentina subjacente e a formação de dentina reparadora constituem a regra e não a exceção. Assim, o potencial curativo do complexo dentina -polpa é muito mais elevado do que se supunha no passado. Com isso, o tratamento da cárie aguda deve dirigirse a deter a infecção e procurar a cura da dentina pela esclerose e reparação. Atualmente, isso pode ser conseguido pela remoção de parte da dentina infectada durante a fase aguda do processo, colocação de um material forrador que promova ação bactericida ou bacteriostática e o selamento da cavidade com material provisório, por determinado período de tempo (MASSLER, 1967).

Durante o processo carioso, a dentina sofre uma considerável perda de minerais. Eidelman, Finn e Koulourides (1965), avaliando a capacidade de remineralização da dentina cariada com o hidróxido de cálcio, encontraram resultados positivos, medidos pelo aumento de conteúdo fosfórico do tecido afetado.

As bactérias seladas abaixo de restaurações provisórias, durante o tratamento expectante, permanecem viáveis durante períodos de tempo consideráveis (SHOVELTON, 1968).

$\mathrm{O}$ uso de um efetivo agente que seja bactericida ou bacteriostático ajuda a eliminar ou a diminuir a quantidade desses microorganismos residuais na dentina cariada. Isso se torna necessário em lesões profundas, próximas à polpa, não só para deter a progressão do processo carioso, pois a mesma diminui bastante com o preenchimento da cavidade por um ma- 
terial selador, mas também para eliminar possíveis microorganismos sobreviventes e erradicar possíveis focos de crescimento bacteriano que podem eventualmente injuriar a polpa dental (BESIC, 1943).

Diversas pesquisas que investigam o estado bacteriológico da dentina cariada, após determinado período de tempo de realização do tratamento expectante, constataram que o número de microrganismos pode ser bastante reduzido, o que pode ser explicado pela redução ou ausência de atividade metabólica (KING et al., 1965; APONTE; HARTSOOK; CROWLEY, 1966; WEERHEIJM et al., 1997; MALTZ et al., 2002).

\section{DISCUSSÃO}

Estudos realizados através de eletromicrografias evidenciaram que diferentes zonas de degeneração do dente, na progressão da cárie, baseiam-se na diminuição da invasão bacteriana. A zona mais superficial é caracterizada pela completa descalcificação e decomposição da dentina (zona infectada). Uma área de descalcificação incipiente, em que a bactéria tenha invadido os túbulos, é a segunda zona. Nessa região, túbulos esclerosados são encontrados com seu lúmem obliterado por material calcificado. Fibras colágenas são também evidentes nessa região. $\mathrm{Na}$ camada mais profunda da área de descalcificação, uma pequena quantidade de túbulos contém microorganismos (zona contaminada) (BERNICK; WARREN; BAKER, 1954).

Avaliando diferenças entre cáries ativas e paralisadas, constatou-se que as primeiras são mais permeáveis que as segundas. A coloração por corantes das camadas dos dentes revelou diferenças entre as partes mais profundas e as superficiais da camada destruída, em que a lesão não é uniformemente ácida (MILLER; MASSLER, 1962).

Cálcio e fósforo são os principais constituintes da fase mineral da dentina. $\mathrm{O}$ estudo desses minerais em dentina cariada tratada com hidróxido de cálcio evidenciou mudanças químicas que provam ser possível a remineralização da dentina cariada (EIDELMAN; FINN; KOULOURIDES, 1965).

Estudo baseado em exame histológico de dentes humanos cariados, através de medidas da distância entre a penetração mais profunda das bactérias e o tecido pulpar, mostrou que a patologia pulpar foi gradual, de acordo com o tipo de lesão e a quantidade de dentina reparadora formada. Espécimes em que a distância entre a bactéria penetrada e a polpa, incluindo a espessura da dentina reparadora, tiveram medidas de $1,11 \mathrm{~mm}$ ou mais revelaram lesões patológicas insignificantes. Quando a dentina reparadora tinha sido invadida pela bactéria, entretanto, patologia de conseqüência real e de natureza irreversível foi encontrada (STANLEY, 1968).

Sarnat e Massler (1965), avaliando a microestrutura de lesões de cáries ativas e paralisadas, constataram importantes diferenças entre elas. Assim, nas lesōes ativas, a zona infectada (rica em bactérias) está colocada dentro da porção profunda da camada necrótica e sobre a porção da camada descalcificada. A porção mais profunda da camada descalcificada encontra-se livre de bactérias e contém muitos cristais grandes, presumivelmente formados pela precipitação de apatita dissolvida pelos ácidos bacterianos. A esclerose começa inicialmente na junção entre a camada descalcificada e a dentina normal. As camadas mais profundas estavam livres de bactérias. Nas lesões paralisadas, na zona superficial rica em bactérias, a maioria dos corpos das bactérias intratubulares foi desintegrada e coalesceu. A zona intertubular parece ter se tornado mais mineralizada. Nas camadas mais profundas, o conteúdo intratubular foi hipermineralizado e obliterado (esclerosado). A calcificação parece ser contínua com a zona peritubular, sendo que essa área estava livre de bactérias.

O tratamento expectante é um procedimento simples, que possui suma importância no que se refere à preservação da vitalidade dental. Representa um procedimento conservador, dentro da filosofia preventiva, na qual a preservação da estrutura dentária constitui-se em fator essencial para garantia de sucesso do procedimento restaurador (FRANCO; FREITAS; D'ALPINO, 2000). 


\section{CONCLUSÃO}

Com a evolução dos conhecimentos na área da biologia dentária, frente às agressões, como lesões de cárie, a possibilidade de intervenção mínima no órgão pulpar é uma realida- de, através da realização do tratamento expectante, buscando-se a maior conservação e preservação do dente, o que constitui atualmente uma real possibilidade de tratamento clínico, desde que seja executado respeitando-se os conhecimentos científicos e critérios técnicos.

\title{
Biological aspects in the process of repair in expectant treatment
}

\begin{abstract}
The expectant treatment is a form of conservative treatment of the pulp that looks for to avoid the pulpal exposure, still offering to the tooth repair conditions in a reversible phase, and to promote the remineralization of the affected dentine, being guided for that in biological knowledge on carious process, nature and characteristics of the different caries lesions and the answers of the dental tissue to this destructive process. This is a practical and safe therapy that can be indicated in the modern restorative dentistry. The purpose of this paper is to accomplish a literature review on clinical and biological important aspects, involved in the tooth process repair submitted to the expectant treatment and supplying scientific subsidies for its safe indication.
\end{abstract}

Keywords: expectant treatement - dentine - pulp; bacteria - dentine - pulp;

\section{REFERÊNCIAS}

APONTE, A.J.; HARTSOOK, J.T.; CROWLWY, M.C. Indirect pulp capping success verified. J. Dent. Child., Fulton, v.33, n.3, p.164-166, 1966.

BARBER, D.; MASSLER, M. Permeability of active and arrested carious lesions to dyes and radioactive isotopes. J. Dent. Child., Fulton, v.23, p.54-68, 1964.

BERNICK, S.; WARREN, O; BAKER, R.F. Electron microscopy of carious dentin. J. Dent. Res., Alexandria, v.33, n.1, p.20-26, Feb. 1954.

BESIC, F.C. The fate of bacteria sealed in dental cavities. J. Dent. Res., Alexandria, v.22, p.349-354, 1943.

BEUST, T.B. Resistence to caries. J. Dent. Res., Alexandria, v.11, n.5, p.619-632, May 1931.

BJØRDAL, L.; LARSEN, T.; THYLSTRUP, A. Clinical and microbiological study of deep carious lesions during stepwise excavation using long treatment intervals. Caries Res., Basel, v.31, p.411-417, Sept. 1996.

BRADFORD, E.W. The dentine, a barrier to caries. Br. Dent. J., London, v.109, n.10, p.387-399, Nov. 1960.

EIDELMAN, E.; FINN, S.B.; KOULOURIDES,T. Remineralization of carious dentin treated with calcium hydroxide. J Dent. Child., Fulton, v.32, n.4, p.218-225, 1965.

FISHER, F.J. The viability of micro-organisms in carious dentine beneath amalgam restorations. Br. Dent. J., London, v.121, n.9, p.413-416, Nov. 1966.

FRANCO, E.B.; FREITAS, A.B.D.A.; D' ALPINO, P.H.P. Tratamento expectante prévio à restauração estética: procedimento simples, seguro e com sucesso. Jbc: J. Bras. Clin. Estet. Odontol., Curitiba, n.21, p.14-19, 2000.

HEYIRAAS, K.J.; MJÖR, I.A. Pulp-dentin 
biology in restorative dentistry. Part 3: Pulpal inflammation and its sequelae. Quintessence Int., Berlin, v.32, n.8, p.611-625, 2001.

KING, J.B. et al. Indirect pulp capping: a bacteriologic study of deep carious dentine in human teeth. Oral Surg. Oral Med. Oral Pathol., St. Louis, v.20, n.5, p.663-671, Nov. 1965.

LEKSELL, E. et al. Pulp exposure after stepwise versus direct complete excavation of deep carious lesions in young posterior permanent teeth. Endod. Dent. Traumatol., Copenhagen, v.12, p.192-196, 1996.

MALTZ, M. et al. A clinical, microbiologic, and radiographic study of deep caries lesions after incomplete caries removal. Quintessence Int., Berlin, v.33, n.2, p.157-158, Feb. 2002.

MASSLER, M. Pulpal reactions to dental caries. Int. Dent. J., London, v.17, n.441-460, 1967.

MILLER, W.A.; MASSLER, M. Permeability and staining of active and arrested lesions in dentine. Br. Dent. J., London, v.112, n.5, p.187-197, Mar. 1962.

MJÖR, I.A.; FERRARI, M. Pulp-dentin biology in restorative dentistry. Part 6:

Reactions to restorative materials, toothrestoration interfaces, and adhesive techniques. Quintessence Int., Berlin, v.33, n.1, p.35-61, 2002.

MJÖR, I.A.; HEYIRAAS, K.J. Pulp-dentin biology in restorative dentistry. Part 1: Normal structure and physiology. Quintessence Int., Berlin, v.32, n.6, p.427-446, 2001.
PEREIRA, J.C.; BERBERT, A; SEGALA, A. D. Long-term clinical and radiographic evaluation of teeth submitted to indirect pulp capping. J. Dent. Res., Alexandria, v.76, p.179, 1997. Special issue.

RITTER, A.V.; BARATIERI, L.N.; MONTEIRO JR, S. Proteção do complexo dentino-pulpar. São Paulo: Santos, 2003. (Caderno de dentística)

SARNAT, H.; MASSLER, M. Microstruture of active and arrested dentinal caries. J. Dent. Res., Alexandria, v.44, n.6, p.1389-1401, Dec. 1965.

SHOVELTON, D.S. A study of deep carious dentine. Int. Dent. J., London, v.18, n.2, p.392405, June 1968.

STANLEY, H.R. Design for a human pulp study I. Oral Surg. Oral Med. Oral Pathol., St. Louis, v.25, n.4, p.633-647, Apr. 1968.

TZIAFAS, D.; SMITH, A.J.; LESOT, H. Designing new treatment strategies in vital pulp therapy. J. Dent., Kidlington, v.28, p.77-92, 2000 .

WEERHEIJM, K.L. et al. Bacterial counts in carious dentine under restorations: 2-year in vivo effects. Caries Res., Basel, v.33, p.130134, June 1997.

WEI, S.H.Y.; KAQUELER, J.C., MASSLER, M. Remineralization of carious dentin. J. Dent. Res., Alexandria, v.47, n.3, p381-391, June 1968.

WEINREB, M.M.; SHARAV, Y.; ICKOWICZ, M. The recuperative capacity of the pulp. Arch. Oral Biol., Oxford, v.17, n.2, p.393-404, 1967. 